\title{
PROPUESTA DE ATRIBUCIÓN DE DOS FRAGMENTOS DEL PAPIRO DE VIENA PVINDOB. G 26008
}

\author{
Carlos Megino Rodríguez \\ Universidad Autónoma de Madrid \\ ATTRIBUTION PROPOSAL OF TWO FRAGMENTS
FROM THE VIENNA PAPYRUS PVINDOB. G 26008
}

El objeto del artículo es argumentar a favor de la atribución de las columnas A y B (según la edición de Most) del Papiro de Viena PVindob. G 26008 a los diálogos Sobre los poetas y Sobre la filosofia de Aristóteles, respectivamente. Primero, se pone en evidencia la autoría aristotélica del texto de ambas columnas, que se analizan en conjunto. Después se aborda la cuestión de si la fuente de los textos del papiro es una sola obra o varias. Se descarta, con diversos argumentos, la tesis de la fuente única, en especial la propuesta de Most de que esa fuente sea el Protréptico de Aristóteles. A continuación, se separa la cuestión sobre la fuente de procedencia de la cuestión sobre la identidad de la obra de la que los textos se han extractado. Se argumenta que mientras que lo más probable es que la obra copiada en el papiro fuera una obra doxográfica de contenido filosófico, la fuente última de los textos, dada la clara diferencia temática entre ellos, sea doble. Finalmente, se defiende que lo más probable es que la fuente de la columna A sea el diálogo Sobre los poetas, y el de la columna B, el diálogo Sobre la filosofia.

Palabras clave: Aristóteles, diálogo Sobre los poetas, diálogo Sobre la filosofia, papiro, crítica textual.
The aim of the article is to argue for the ascription of the columns A and B (after Most's edition) of the PVindob G 26008 to the aristotelian dialogues On poets and On philosophy, respectively. Firstly, it is shown the aristotelian authorship of the text of both columns, which are analyzed as a whole. Then, it is dealt with the question if the source of the papyrus' texts is either a only work or several ones. It is dismissed, with a wide range of arguments, the view of the unique source, especially the Most's claim that this source is the Aristotle's Protrepticus. Afterward, it is distinguished the question of the source from the question of the indentity of the work which the texts are extracted from. It is argued that, whereas the work copied in the papyrus was most probably a doxographical work of philosophical content, the first source of the texts was double, given the difference of subject between them. Finally, it is defended that the source of column A is most probably the dialogue On poets, and the source of column B, the dialogue On philosophy.

Keywords: Aristotle, dialogue On poets, dialogue On philosophy, papyrus, textual criticism. 
Entre los problemas que suscita una edición de fragmentos está el de determinar qué fragmentos son atribuibles a las obras del autor que se edita, así como el de intentar establecer a qué obras pertenecen o se pueden referir, con qué grado de seguridad y qué tipo de adscripción es la más idónea (cita literal, paráfrasis, testimonio, epítome, extracto, alusión, vestigio, etc...). En el caso de una nueva edición de los fragmentos de los diálogos de Aristóteles, estos problemas no se plantean evidentemente desde cero, pues los anteriores editores los han tenido que afrontar y han aportado soluciones que pueden servir como punto de partida para el trabajo. De este modo, la tarea que se presenta a este respecto es doble: primero, la revisión de los fragmentos aceptados por los editores anteriores, tanto en relación con su autenticidad (si son realmente o no procedentes de Aristóteles y, además, de algunos de sus diálogos), como en relación con la validez de su adscripción a uno u otro diálogo determinado; y segundo, la decisión sobre estas cuestiones respecto de fragmentos conocidos con posterioridad a las últimas ediciones, o ya conocidos, pero no tenidos en cuenta por éstas.

Es en el contexto de esta segunda tarea, la de la adscripción de nuevos fragmentos a los diálogos aristotélicos, en el que se desarrollará el presente trabajo.

Tomaré en consideración dos fragmentos papiráceos que creo que son paradigmáticos para ilustrar los problemas que ofrece en ocasiones la identificación de nuevos fragmentos de los diálogos de Aristóteles, sobre todo cuando éstos no ofrecen ninguna referencia ni al autor ni la obra de la que proceden. Ambos están escritos en sendas columnas que aparecen en un papiro de la Österreichische Staatsbibliothek de Viena, conocido como Papyrus Vindobonensis G 26008 ( Pack $^{2}$ 2564), editado por primera vez por Gomperz en $1886^{1}$, y reeditado varias veces hasta la última edición de Most en $1992^{2}$. Dichas columnas son designadas como columnas A y B por este editor ${ }^{3}$. El texto de la columna A según esta edición, cuyas correcciones textuales seguimos, es el siguiente:

1 T. Gomperz 1886, pp. 19-24.

2 G. W. Most 1992, p. 189 ss. El papiro fue editado también por H. Oellacher 1932, pp. 126-30 y 1938, p. 135 ss., F. Decleva Caizzi-M. S. Funghi 1991, p. 49 ss. y S. Radt 1977, p. 81 (sólo la columna $\mathrm{A}=T G r F 4$, test. IIc 143).

${ }^{3}$ Las cuales coinciden con los denominados por H. Oellacher 1938, p. 138 s., fr. I col. II del grupo $a$ y fr. I del grupo $b$, y por F. Decleva Caizzi - M. S. Funghi 1991, p. 58 ss., col. II del grupo A1 y col. II del grupo B1, respectivamente. 
P. Vindob. G 26008, Col. A 5-32, ed. Most, pp. 190-2: ${ }^{5}$ ó] $\mu \alpha ́ \mid \lambda[1] \sigma \tau \alpha$

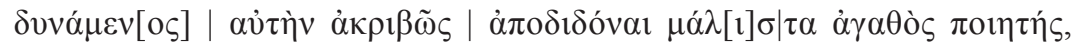

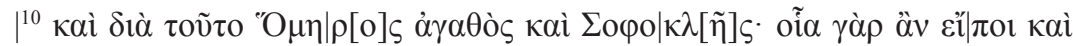

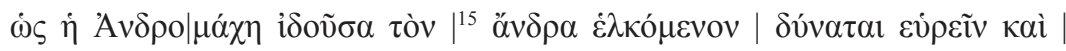

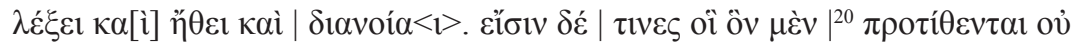

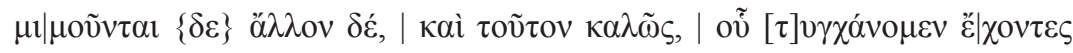

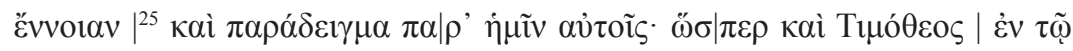

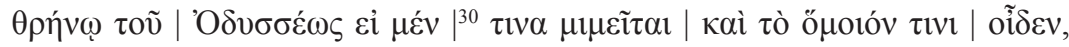

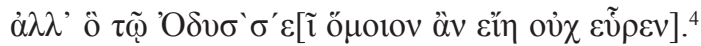

Quien con mayor propiedad es capaz de exponerla ${ }^{5}$ con exactitud, con mayor propiedad es buen poeta, y por eso mismo Homero es bueno, y

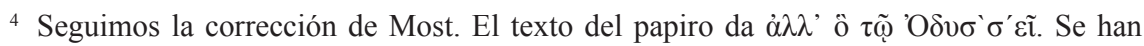
propuesto otras correcciones. Gomperz, p. e., proponía $\dot{\alpha} \lambda \lambda{ }^{\prime} \quad<<\dot{v}>\tau \tilde{\omega}{ }^{\prime} \mathrm{O} \delta v \sigma^{`} \sigma^{\prime} \varepsilon[\tilde{\mathrm{\imath}}$. Oellacher,

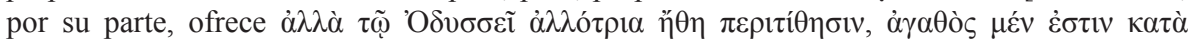

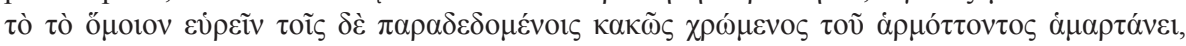
mientras que por una solución más sencilla se decantan Decleva Caizzi-Funghi, que corrige

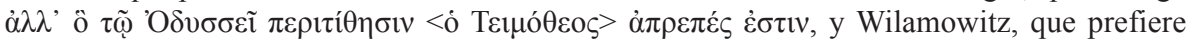

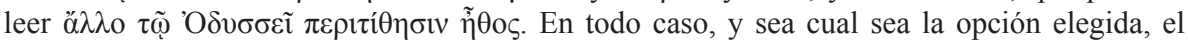
mensaje está claro: lo que Aristóteles reprocha a Timoteo es que, mientras que sabe imitar a gente ordinaria, a Odiseo en cambio lo representa en su lamento de una forma inadecuada e inconveniente para su carácter (cf. Arist., Po. 1454ª30): cf. también F. Decleva Caizzi - M. S. Funghi 1991, p. 67 y G. W. Most 1992, pp. 193, 195.

5 Se suele admitir, desde H. Oellacher 1938, pp. 155, 177, que av̉ińv se refiere a la $\lambda \dot{\varepsilon} \xi 1 \zeta$, en este caso, la elocución necesaria para representar cada personaje del modo más verosímil. No obstante, teniendo en cuenta que en la siguiente frase se fundamenta la consideración de buen poeta no sólo en el uso de la elocución, sino también en el del carácter y el pensamiento,

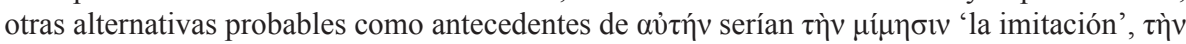

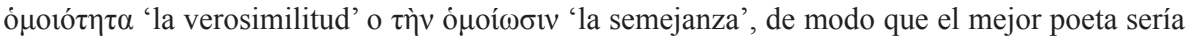
quien domina con exactitud la técnica de la imitación, de la verosimilitud o de la semejanza en la representación poética de caracteres. No creemos (como G. W. Most 1992, p. 196) que sea una refutación de estas alternativas el hecho de que más adelante se diga que ciertos poetas (inferiores) pueden imitar también de forma bella, ya que sigue estando vigente la misma diferencia entre el buen y el mal poeta: la capacidad para imitar de forma verosímil el carácter de un personaje concreto en relación con la caracterización que de él nos transmite la tradición mítica, y no en relación con cualquier otro personaje, independientemente de que esa imitación se haga con exactitud y belleza. La alternativa propuesta por Most 1992, p. 202,

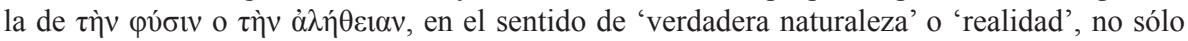
requiere la aceptación previa de su interpretación del fragmento a la luz del Protréptico de Aristóteles, cosa harto dudosa como veremos, sino que supone un uso de pv́бıৎ no atestiguado en la Poética, donde el objeto de la imitación de la poesía son las acciones humanas, no 
también Sófocles; pues es capaz de inventar, en lo tocante a la elocución, al carácter y al pensamiento, las cosas que diría Andrómaca al ver a su marido arrastrado, y cómo $<$ las diría $>^{6}$. Por otra parte, hay ciertos $<$ poetas $>$ que no imitan a quien se proponen, sino a otro - y lo <imitan $>$ bellamente-, de lo cual tenemos casualmente una idea y un modelo entre nosotros mismos: así, por ejemplo, Timoteo en su "lamento de Odiseo"7, si imita a cualquiera y conoce lo que es verosímil para cualquiera, para Odiseo en cambio no ha descubierto lo que sería verosímil.

Como vemos, nos encontramos ante un texto sin indicación de título y sin ninguna referencia interna ni al autor ni a la obra a la que pertenece, de modo que hay que deducir estos datos a partir de su contenido, su estilo y su vocabulario. Respecto de su contenido, se trata de un texto de teoría literaria, en el que se explica el papel que la exactitud en la imitación verosímil de los personajes tiene en la consideración del buen poeta, ilustrándose con un ejemplo el fracaso que para esa consideración supone una imitación poética que no respeta las reglas de lo verosímil en cada personaje. El claro paralelismo entre lo que aquí se dice y el pasaje

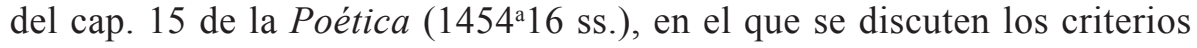
de adecuación ( $\tau$ ò $\alpha \rho \mu o ́ \tau \tau o v)$, verosimilitud ( $\tau$ ò ő $\mu o 10 v)$ y consecuencia ( $\tau$ ò ó $\mu \alpha \lambda$ óv) de los caracteres de los personajes respecto de su imitación o representación dramática, y en el que se cita incluso el lamento de Odiseo como ejemplo $(\pi \alpha \rho \alpha ́ \delta \varepsilon \imath \gamma \mu \alpha)$ de inconveniencia $(\dot{\alpha} \pi \rho \varepsilon \pi \mathrm{o} \tilde{\varsigma})$ e inadecuación

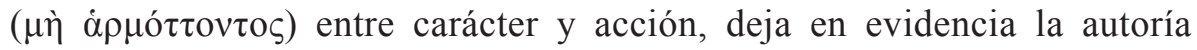
aristotélica del fragmento, lo cual es confirmado por el análisis del estilo y del vocabulario ${ }^{8}$.

la naturaleza como tal, además de que la imitación de la naturaleza no casa bien con la "invención" de la conducta más verosímil para Andrómaca, un personaje fícticio, que se pone como ejemplo de ese tipo de imitación.

${ }^{6}$ Cf. Il. XXII 477-514. Cf. también el escolio a Il. II 791-5 (POxy. 1086, 67 ss.): «Que Homero, cuando retrata a alguien para algo, también le atribuye las palabras adecuadas, es evidente».

7 Fr. 793 Page.

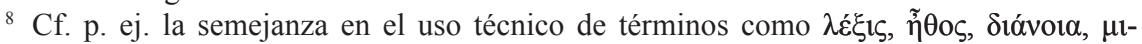

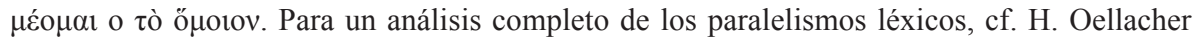
1938, p. 155 ss. 
Esa autoría ha sido reconocida desde hace tiempo9. Sin embargo, la cuestión sobre la obra de procedencia es más complicada, y ello ha tenido como consecuencia que no se haya logrado un acuerdo entre los especialistas. Decimos que la cuestión de la identificación de la obra de procedencia es más complicada, porque antes de decidir un posible candidato entre las obras conocidas de Aristóteles, hay que tener en cuenta el segundo fragmento presente en el mismo papiro, el de la columna B, ya que cabe la posibilidad de que proviniera de la misma obra que el fragmento de la columna $\mathrm{A}^{10}$, y ello obliga a tomar una decisión sobre esa posibilidad antes de decidirse por una u otra obra como fuente. La cuestión consiste entonces en decidir si los dos fragmentos pertenecen a una obra única o a dos obras distintas. Para ello tendremos que ver primero el fragmento de la columna B:

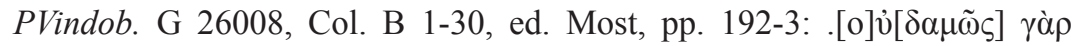

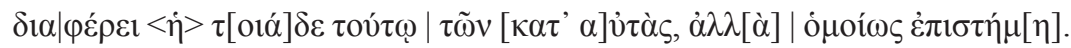

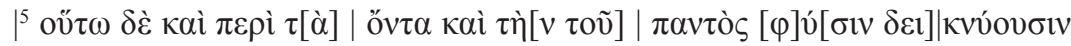

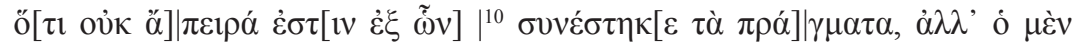

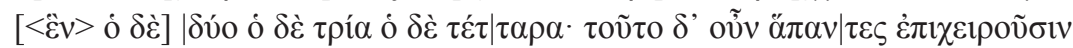

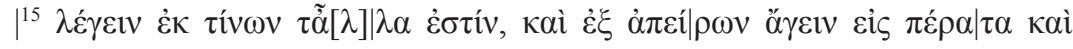

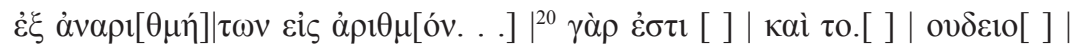

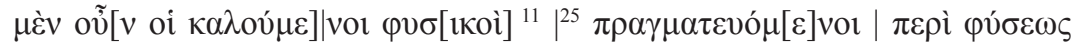

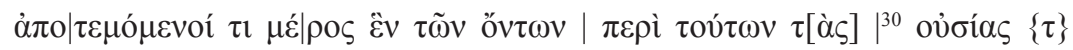
$\lambda \varepsilon \dot{\gamma} \gamma 00 \sigma \mathrm{v} \ldots{ }^{12}$

9 Cf. p. ej. H. Oellacher 1938, pp. 137, 177 ss.; A. Rostagni 1955b, p. 324 s.; R. Janko 1987, p. 190 ss.; 1991, p. 55; G. W. Most 1992, p. 194; F. Decleva Caizzi - M. S. Funghi 1991, p. 56, por su parte, proponen la hipótesis de que pudiera provenir del ámbito del primer Perípato, sin mayor argumentación al respecto. La hipótesis no es del todo descartable, pero, dado que todos los indicios apuntan a Aristóteles mismo, y que conocemos mejor sus doctrinas que las de sus continuadores, proponer como autor a alguno de sus discípulos inmediatos que repitiera las mismas opiniones que el maestro no parece estar más fundamentado.

${ }^{10}$ Las evidencias papirológicas apuntan a que ambos han sido escritos por el mismo escriba, aunque no es seguro que también lo fueran en el mismo rollo: cf. F. Decleva Caizzi-M. S. Funghi 1991, p. 51 ss.

${ }^{11}$ Conjetura de Wessely en Gomperz ad loc.

${ }^{12}$ Siguen 15 líneas con palabras y letras sueltas. 
Pues de ningún modo se diferencia en esto tal <ciencia ?> de las particulares, sino que es una ciencia en el mismo sentido ${ }^{13}$. Y así también, respecto de los seres y la naturaleza del universo, <los filósofos naturales $>$ muestran que no son ilimitadas las cosas de las que está compuesto, sino que uno <propone> una, otro, dos, otro, tres, y otro, cuatro; todos intentan, pues, explicar de qué cosas proceden todas las demás, y llevar las cosas ilimitadas a unos límites, $\mathrm{y}<$ poner $>$ a las cosas innumerables un número ${ }^{14}[\ldots]$, pues es $[\ldots]$ y $[\ldots]$ ninguno [...] los llamados filósofos naturales, que investigan la naturaleza seccionando una sola parte de los seres, declaran las entidades concernientes a ellos ${ }^{15}$.

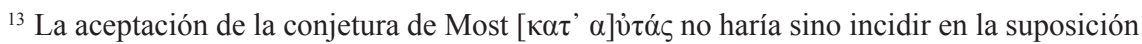
más probable de que lo que se quiere decir es que se trata de una ciencia particular. La frase siguiente, que pretende ilustrar este punto, nos revela que se trata de una referencia a la filosofía natural, propia de aquellos filósofos que proponían, como principios de todas las cosas, elementos de naturaleza material, que serían el sustrato y la causa constitutiva de la realidad. Unos filósofos propusieron que tal principio era único, como Tales, Heráclito o Parménides; otros, que era doble, como Leucipo y Demócrito (lo lleno y lo vacío) o los pitagóricos (lo limitado y lo ilimitado); otros, triple, como Platón (el Uno, lo Grande y lo Pequeño); y otros, cuádruple, como Empédocles (aire, agua, tierra y fuego): cf. Arist., Metaph. $983^{\mathrm{b}} 6$ ss., y también, $P h .189^{\mathrm{b}} 12-16$.

${ }^{14}$ Parece aludirse al intento, mediante la postulación de principios finitos de las cosas, de reducir la multiplicidad natural a sus principios elementales. No poseemos en los tratados conservados de Aristóteles una doctrina similar atribuida a los filósofos naturales anteriores (cf. G. W. Most 1992, p. 194), sólo la argumentación propia aristotélica de que los primeros principios no pueden ser infinitos, entre otras cosas, porque postulando dos o tres principios, se consigue la misma finalidad explicativa que si se postulan principios infinitos, como hace Anaxágoras (Arist., Ph. 189a12-17, Cael. 302 11-24). Sí existe, en cambio, cierto paralelismo con los pasajes de la Física en los que se trata del número de los principios: p. ej. $184^{\mathrm{b}} 15$ ss.: «Necesario es que haya o un principio o muchos; y si es uno, que sea inmóvil, como afirman Parménides y Meliso, o que se mueva, como <afirman> los filósofos naturales, algunos de los cuales andan diciendo que el primer principio es aire, y otros, que es agua; y si son muchos,

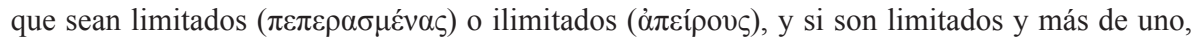
serán dos, tres, cuatro o cualquier otro número».

${ }^{15}$ Se trata de una referencia al método y al objeto de estudio de la física en tanto que ciencia particular, seguramente en contraposición con la ciencia universal, es decir, la ciencia de lo que es en tanto que algo que es, tal como se deduce de Metafísica, 1003a215 , un pasaje íntimamente paralelo a éste (cf. las coincidencias textuales y, en especial, el uso técnico del verbo $\dot{\alpha} \pi$ o $\varepsilon \dot{\mu} \mu \nu \omega$, infra n. 25). Las ciencias particulares, como la física o las matemáticas, se caracterizan por restringir su objeto de estudio a sólo una parte de lo existente, dando cuenta de las entidades (ov̉oíaı) de los seres que entran en su dominio, es decir, de los primeros elementos y de las substancias procedentes de éstos (cf. Cael. $298^{\text {a } 27}$ ss. y Most 1992, p. 216). 
Enseguida vemos que el texto presenta una temática distinta del anterior, consistente ahora, por lo que parece, en exponer el método y objeto de estudio de la física ${ }^{16}$ en tanto que ciencia particular, lo que se ilustra mediante el ejemplo de los filósofos naturales, que intentan explicar la innumerable multiplicidad de las cosas a partir de uno o unos pocos principios elementales, a fin de convertir lo ilimitado en un ámbito limitado de estudio, siendo esa restricción del ámbito de estudio a los seres naturales lo que caracteriza a la física como ciencia particular.

El lenguaje y el contenido del fragmento son también claramente aristotélicos, tal como evidencia su comparación con otros pasajes paralelos de la Metafísica ( $983^{\mathrm{b}} 6$ ss., 1003ª $\left.21-26\right)$, la Física (184 10 ss.) y el Sobre el cielo (268 1 ss., $302^{\mathrm{b}} 10 \mathrm{ss}$.), donde se habla de los métodos y los principios de la filosofía natural en comparación con los propuestos por filósofos anteriores. Podemos asumir, pues, que los dos fragmentos del papiro están extractados de los escritos de Aristóteles. La cuestión entonces radica en si, dada la diferencia de tema entre los dos fragmentos, se puede sostener la tesis de una sola obra como fuente de ambos o no.

La defensa de una única obra como fuente requiere que ésta sea de temática lo suficientemente amplia como para acoger un texto sobre la verosimilitud en la imitación poética y otro sobre los principios y el objeto de la física como ciencia particular. Así, por ejemplo, Maria Serena Funghi y Fernanda Decleva Caizzi ${ }^{17}$ proponen como hipótesis una obra no precisada cuyo tema principal sea la poética, y en la que el fragmento B sería un mero excursus introducido como ejemplo. Sin embargo, sus diversas propuestas para encontrar un punto de contacto entre los dos fragmentos que hagan esta hipótesis plausible son poco consistentes ${ }^{18}$.

El último editor del papiro, Glenn W. Most ${ }^{19}$, que es el que más y mejor ha argumentado en favor de la tesis de la obra única, propone como candidato el Protréptico de Aristóteles, con el que ambos fragmentos presentarían notables similitudes de contenido ${ }^{20}$. Según Most, el fragmento de la columna

\footnotetext{
${ }^{16}$ Entendida, evidentemente, en sentido aristotélico, como ciencia de los seres naturales y de sus principios y causas (cf. Arist., Ph. $184^{\mathrm{a}} 10 \mathrm{ss}$.).

${ }^{17}$ F. Decleva Caizzi-M. S. Funghi 1991, pp. 70-73.

${ }^{18}$ Cf. la fundamentada crítica de Most (ibíd. 198 s.) a esas propuestas.

${ }^{19}$ G. W. Most 1992, p. 197 ss.

${ }^{20}$ Esa misma tesis es compartida por G. Arrighetti 1991, 34 y 1996, 59 n. 1, el último autor que se ha ocupado del papiro.
} 
A debe verse a la luz de los fragmentos 46-51 del Protréptico ${ }^{21}$, donde Aristóteles defiende la utilidad práctica de la filosofía acudiendo al ejemplo de las artes, como la gimnasia, la medicina o la arquitectura, cuya excelencia y utilidad requieren tener un adecuado conocimiento de la naturaleza de las cosas sobre las que ejercen su actividad. Así, del mismo modo que el buen médico, el buen maestro de gimnasia o el buen arquitecto es beneficioso en su trabajo porque es buen conocedor de la naturaleza del cuerpo y se sirve de instrumentos de medida extraídos del orden natural, el filósofo es beneficioso para la sociedad porque conoce la verdad de la naturaleza y extrae sus pautas de actuación de la imitación de los primeros principios, en función de las cuales juzga lo que es justo y provechoso y, por tanto, puede promulgar las mejores leyes y realizar acciones rectas y buenas. Según Most, el fragmento de la columna A encajaría perfectamente en la argumentación de este pasaje, si se lo considera no como una disquisición sobre el mejor uso de los recursos poéticos en la representación de caracteres, sino como una alusión al arte poética para ilustrar el valor del conocimiento de la verdadera realidad, donde la definición del buen poeta como aquel que es capaz de imitar con exactitud la naturaleza humana, constituiría otro ejemplo de que la excelencia de cualquier actividad se funda en el conocimiento e imitación exacta de la naturaleza, los cuales sólo los proporciona en su máximo grado la filosofía.

Sin embargo, esta interpretación se enfrenta a serias objeciones, que creo que consiguen invalidarla. En primer lugar, no poseemos el contexto del fragmento de la columna A y, por consiguiente, carecemos de los elementos de juicio precisos para juzgar la intención real del autor al escribirlo, si era la discusión técnica o la ejemplificación ilustrativa. En segundo lugar, Most incurre en una petición de principio, que es la de basar el paralelismo entre el fragmento y el Protréptico en la premisa de que la consideración del buen poeta en el papiro se funda en la exposición exacta de la naturaleza ( $\varphi v ́ \sigma i \varsigma$, que sería lo referido por el pronombre av̉ińv), lo que a su vez se pretende demostrar a través del paralelismo con el Protréptico. Además, la tesis de

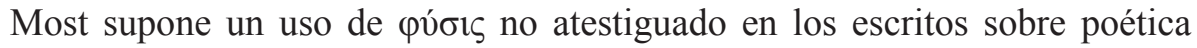
de Aristóteles, donde el objeto de la imitación de la poesía son las acciones humanas, no la naturaleza real de los personajes. Y aun cuando esto fuera así, esa imitación o representación de la naturaleza no casaría bien con el hecho

${ }^{21}$ Arist., Protr. frr. 46-51 Düring = Iambl., Protr. 54.10-56.4 Pistelli. 


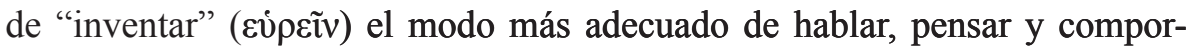
tarse para Andrómaca, un personaje ficticio, que se pone como ejemplo en el papiro de ese tipo de imitación. En tercer lugar, hay una total carencia de coincidencias textuales con los pasajes del Protréptico en los que se dice que podría encajar, además de no explicarse por qué el texto del Protréptico no hace ninguna mención del arte poética, mientras sí la hace de otras artes, como la medicina, la gimnástica o la arquitectura. En cuarto lugar, el texto del fragmento es tan especializado, que resulta más bien contraproducente para servir de ejemplo en un contexto como el del Protréptico, donde los ejemplos que se aducen están siempre claramente relacionados con el tema principal de la obra, que es la exhortación a la filosofía ${ }^{22}$. El contexto natural del fragmento, como confirma su evidente paralelismo con el cap. 15 de la Poética, tiene que ser el de una obra de teoría literaria.

En cuanto al fragmento de la columna B, Most cree que encajaría bien en el contexto de los frr. 32-36 del Protréptico $^{23}$, en los que se hace una analogía entre la ética y la ciencia natural, sobre la base de que en ambas es más seguro (y necesario) el conocimiento de lo finito y ordenado que de lo contrario, es decir, el conocimiento de los elementos que el de las cosas que proceden de éstos, ya que de los elementos se generan y se componen todas esas cosas, y si no se conocen los elementos, como el fuego, el aire o el número, tampoco se conocerá lo demás. Para Most, la columna B presentaría una analogía similar entre la ciencia natural y la actividad filosófica, basada en el hecho de que ambas parten de la multiplicidad ilimitada de los seres para llegar a sus elementos constitutivos, los cuales, siendo ordenados y finitos en número, son más fácilmente cognoscibles que la multiplicidad de los seres físicos.

En este caso, se puede ver también la endeblez del paralelismo entrevisto por Most. En el pasaje del Protréptico, el objetivo es demostrar la accesibilidad de la filosofía al conocimiento, sea como ciencia de la virtud, o sea como ciencia de la naturaleza y de la verdad, mostrando que su objeto de conocimiento son los principios y causas de las cosas, que son las entidades más cognoscibles y, además, las que posibilitan conocer la multiplicidad de los seres. En cambio, en la columna B del papiro lo que se pretende es mos-

\footnotetext{
${ }^{22}$ Como prueban los mismos ejemplos aducidos en los fr. 47 y 49 del Protréptico, entre los cuales la mención, por ejemplo, del lamento de Odiseo de Timoteo, estaría fuera de lugar.

${ }^{23}$ Arist., Protr. frs. 32-36 Düring = Iambl., Protr. 37.26-39.8 Pistelli.
} 
trar el objeto y método de una ciencia particular a través del ejemplo de los filósofos naturales, que deben afrontar el conocimiento de la multiplicidad de lo real deduciéndola de un número limitado de principios elementales. Es cierto que en ambos casos se señala que el objeto de la ciencia debe ser lo delimitado y ordenado, y que a partir de esto debe deducirse el conocimiento de las demás cosas, pero el contexto y el fin del discurso en uno y otro caso son diversos: en el Protréptico, la ciencia de la que se habla es la filosofía, que se presenta como un saber general que abarca toda la realidad, sea el alma, las entidades divinas o los seres naturales, y la alusión a los primeros principios como su objeto de estudio es motivada por el deseo de demostrar su accesibilidad al conocimiento humano; en el papiro, la ciencia de la que se habla es una ciencia particular, cuyo objeto de estudio está, por definición, limitado a un determinado ámbito de la realidad y cuya mención parece obedecer al deseo de diferenciarla de otro saber más general, de modo similar a como ocurre en un pasaje de la Metafísica muy similar $^{24}$. Si el texto de la columna B procediera del pasaje del Protréptico citado, cabría esperar que hubiera esa coincidencia entre los fines de uno y otro que vemos que falta y que se apreciara en él un carácter protréptico del que carece.

A la vista de tales objeciones, la pretensión de Most de hacer derivar las columnas A y B del Protréptico aristotélico atendiendo a supuestas semejanzas de contenido se revela muy débil. Tampoco es más sólido el argumento que le sirve a $\mathrm{Most}^{25}$ de punto de partida para proponer el Protréptico: las supuestas evidencias papirológicas que apuntan a que los dos fragmentos fueron escritos en el mismo rollo, lo que hace muy probable su pertenencia a la misma obra y permite privilegiar la hipótesis de la adscripción a una obra única a pesar de las diferencias de contenido. Decimos que no es sólido porque las evidencias papirológicas son neutras a ese respecto. Lo único que indican con cierta seguridad es que ambas columnas fueron escritas por el mismo escriba, pero no permiten decidir (en contra de lo que sugiere Most) si lo fueron en un mismo rollo o en dos diferentes

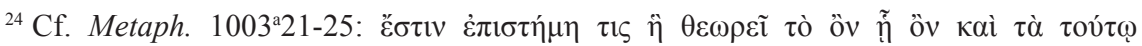

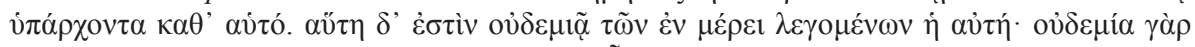

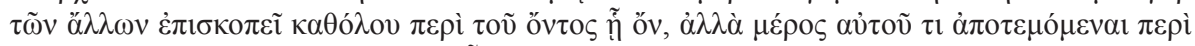

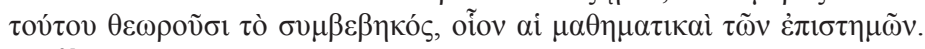

${ }^{25}$ G. W. Most 1992, pp. 197, 207. 
$y$, por tanto, si formaban parte con alta probabilidad de una sola obra o de dos diferentes ${ }^{26}$.

De hecho, incluso aceptando que los fragmentos en cuestión estuvieran escritos en un mismo rollo y pertenecieran a una misma obra, el planteamiento de Most y de los defensores de la hipótesis de la obra única adolece de un vicio de origen, que es el de asumir de antemano la identidad de la obra escrita en el papiro y la obra fuente de la que procede el texto de éste. No hay por qué suponer necesariamente que el origen último de los fragmentos fuera también una sola obra. Es posible que el escriba copiara en el mismo rollo un comentario o una obra de contenido doxográfico (o parte de ella) que contuviera extractos y citas de Aristóteles sobre diversos temas, entresacados de varias de sus obras. Sin necesidad de negar la existencia de una única obra escrita en el rollo de papiro, se puede explicar la clara diferencia temática entre los dos fragmentos asumiendo que éstos fueron extractados de dos obras distintas y después compilados en una única obra, que fue la copiada en el rollo de papiro. Plantear la objeción de que es muy difícil que hubiera un texto que contuviera fragmentos de esa extensión con una temática tan diversa, y de que postular una antología de textos filosóficos es una quimera inventada para la ocasión, como hace $\mathrm{Most}^{27}$, no tiene ninguna fuerza probatoria. De hecho, existen numerosos ejemplos de textos que podían incluir citas de obras de Aristóteles de extensión y temática similar a las del papiro, como puede ser el Banquete de los eruditos de Ateneo ${ }^{28}$, las Cuestiones convivales de Plutarco ${ }^{29}$, las Vidas de filósofos

${ }^{26}$ Cf. F. Decleva Caizzi - M. S. Funghi 1991, p. 52 n. 9, p. 54 y pp. 70-73, quienes a la vista de las características formales de la escritura y del estado del papiro, dejan abiertas ambas posibilidades sin excluir ninguna de ellas, aunque para la hipótesis de que se tratara de una misma obra proponen como posible candidato un escrito de naturaleza imprecisa cuyo tema principal fuera la poética e incluyera como excursus el fragmento relativo a los filósofos naturales.

${ }^{27}$ G. W. Most 1992, p. 207: «A chimera invented for the occasion».

${ }^{28}$ Que p. ej. cita en 505b-c un fragmento literal de temática literaria del diálogo de Aristóteles Sobre los poetas (fr. 72 Rose $^{3}=15$ Gigon); en 429c-d (fr. 107 Rose $^{3}=669$ Gigon), 464c-d (fr. 110 Rose $^{3}=672$ Gigon) y 641d-e (fr. 104 Rose $^{3}=675$ Gigon), otros tres sobre temática convival procedentes del diálogo Sobre la borrachera; y en 556d-e (fr. 144 Rose $^{3}=$ 42 Gigon), otro que puede ser adscrito tanto a las aristotélicas Cuestiones homéricas como al diálogo Sobre el amor.

${ }^{29}$ Que cita en $733 \mathrm{c}$, un fragmento aristotélico que podría proceder del diálogo Sobre la filosofia (fr. 43 Rose $^{3}=734$ Gigon), en 650a, otro procedente del diálogo Sobre la borrachera 
ilustres de Diógenes Laercio ${ }^{30}$ o la Antología de Juan Estobeo ${ }^{31}$. Estas obras no sólo parafrasean, resumen o extractan textos de Aristóteles, también los citan literalmente y, en ocasiones, con bastante extensión, de modo similar a como ocurre en el papiro.

Tiene razón Most $^{32}$ cuando dice que es preferible considerar la posibilidad de un tratado filosófico en el que los dos fragmentos encajen, que considerar la de un compendio. Sin embargo, ante la falta de un candidato lo suficientemente plausible entre las obras de Aristóteles, existen más probabilidades de encontrarlo entre la relativamente abundante literatura doxográfica, de la que hemos citado algunos ejemplos. Con ello no quiero decir que alguna de las obras mencionadas (o una parte de ellas) sea la que copia el escriba, sino sólo que lo más probable es que la obra copiada, si efectivamente era única, fuera una obra de este tipo, y que aceptar esta posibilidad es independiente de la cuestión de la procedencia última de los fragmentos del papiro. Si admitimos que no existe entre las obras conocidas de Aristóteles un candidato único plausible para ser la fuente de los dos fragmentos, hemos de pensar entonces en dos obras distintas cuyo contenido sea lo más similar posible al de los fragmentos. Obras, repetimos, que serían la fuente última de éstos, no necesariamente las que fueron copiadas en el papiro.

Pero entonces, ¿cuáles pueden ser éstas? Se han hecho varias propuestas, sobre las que no se ha llegado a ningún consenso. Así p. e., Oellacher ${ }^{33}$ pensaba que la fuente de la columna A, al no ser la Poética que conocemos, tendría

(fr. 108 Rose $^{3}=1015$ Gigon), y en 734d, otro adscribible al diálogo Sobre la educación (fr. 62 Rose $^{3}=735$ Gigon), aunque, salvo esta última, no son citas literales.

${ }^{30}$ Que ofrece citas y testimonios de una gran variedad de obras perdidas de Aristóteles de distinta temática, como los diálogos Sobre la filosofía (I 8.5-9.1 = fr. 6 Rose $^{3}=23$ Gigon), Sobre los poetas (VIII 57-58 $=$ fr. 70 Rose $^{3}=17$ Gigon, III $48=$ fr. 72 Rose $^{3}=14$ Gigon etc.), Grilo (II $55=$ fr. 68 Rose $^{3}=38$ Gigon) o el Sofista (VIII $57=$ fr. 65 Rose $^{3}=39,1$ Gigon).

${ }^{31}$ Que cita, seguramente a través de fuentes intermedias, amplios fragmentos literales de varias obras de Aristóteles, como Sobre las pasiones (III 20.46, 55 = frs. 661, 660 Rose $^{3}=107$, 108 Gigon, que también podrían proceder del diálogo Sobre la justicia), y Sobre la nobleza (IV 29 A 24, 25, C 52 = frr. 91, 92, 94 Rose $^{3}=$ 68, 69, 70 Gigon), y también alusiones más breves del Protréptico (IV $32.21=$ fr. 50 Rose $^{3}=54$ Gigon) y del diálogo Sobre la filosofía (III $21.26=$ fr. 3 Rose $^{3}=28$ Gigon).

${ }^{32}$ G. W. Most 1992, 200.

${ }^{33}$ H. Oellacher 1938, pp. 177-181. 
que ser una obra lo suficientemente elaborada, argumentada y sistemática como para que pudiera servir todavía de manual en una escuela del Fayûm (Egipto), en el siglo III d. C., que es el lugar de procedencia y la fecha de datación del papiro ${ }^{34}$. Esa obra sería, para él, la que tiene por título Tratado

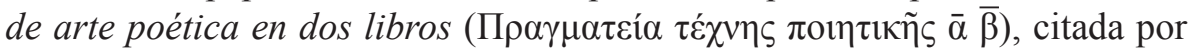
Diógenes Laercio en el $n^{\circ} 83$ de su catálogo de obras de Aristóteles, ya que la argumentación utilizada en el papiro era demasiado sistemática para pensar en el diálogo Sobre los poetas, una obra, según él, juvenil y de carácter ligero y anecdótico. Sin embargo, nada se sabe de esa supuesta obra perdida, y lo más probable, como se acepta hoy de forma general, es que ese Tratado no sea otra cosa que la Poética misma en dos $\operatorname{libros}^{35}$. En cuanto a la columna B, Oellacher proponía como fuente una obra doxográfica aristotélica, que podría ser la titulada Sobre los principios o Sobre la naturaleza (Пepì $\dot{\alpha} \rho \chi \tilde{\omega} v$ iे $\varphi v ́ \sigma \varepsilon \omega \varsigma, \mathrm{n}^{\circ} 21 \mathrm{Hes} .=41$ D. L.?), o bien la obra Sobre los elementos

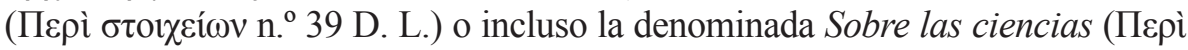
$\dot{\varepsilon} \pi \iota \sigma \tau \mu \tilde{\omega} \nu$ n. ${ }^{\circ} 26$ D. L.). Sin embargo, nada sabemos de estas obras aparte de lo que se puede deducir de sus títulos y, por consiguiente, la atribución a cualquiera de ellas resulta meramente conjetural.

Sobre la columna B no se ha hecho, que sepamos, ninguna otra propuesta sobre su procedencia que las ya señaladas, quedando la cuestión abierta. Sobre la columna A, en cambio, sí se ha planteado otra posibilidad, que es la de que su texto provenga en última instancia del diálogo aristotélico Sobre los poetas ${ }^{36}$.

${ }^{34}$ La datación en la primera mitad del siglo III d. C. ha sido establecida sobre la base del tipo de escritura, similar a la de otros papiros de finales del siglo II y principios del III (cf. F. Decleva Caizzi - M. S. Funghi 1991, p. 51 n. 6). Esa datación ya fue propuesta por H. Oellacher 1938, p. 135 y ha sido compartida por R. Janko 1991, p. 54. En cambio, G. W. Most 1992, p. 190, como ya hiciera Karabacek (ap. Oellacher 1938, p. 136) prefiere retrotraer el papiro al s. II d. C. Nótese, en relación con la argumentación que emprenderé a continuación, que en esa época todavía se copiaban los diálogos de Aristóteles (o partes de ellos, como testimonian p. e., las citas y alusiones que de ellos hacen autores contemporáneos como Ateneo, Clemente de Alejandría, Diógenes Laercio o Sexto Empírico, eso sin contar las referencias de autores posteriores como Simplicio o Juan Estobeo), lo que hace cronológicamente posible que el texto del papiro pudiera ser incluso una cita directa de algunos de esos diálogos.

${ }^{35}$ Cf. p. ej. A. Rostagni 1955b, p. 325, R. Laurenti 1987, p. 283 n. 3 (con ulteriores referencias), R. Janko 1984, pp. 63-66, 1991, p. 55. En contra, p. ej. D. de Montmollin 1951, p. 178 s., y I. Düring $1990^{2}$, p. 205, quienes creen que el Tratado citado por Diógenes Laercio pudo ser una obra independiente.

${ }^{36}$ Cf. A. Rostagni 1955b, p. 325 y R. Janko 1987, pp. 62, 190; 1991, p. 55. 
Pues bien, me propongo, si no demostrar, sí al menos defender con fundados argumentos, que esta posibilidad es la más probable respecto de la columna $\mathrm{A}$; y también que, respecto de la columna $\mathrm{B}$, un candidato muy verosímil como fuente es el diálogo de Aristóteles Sobre la filosofía.

Respecto de la columna A, los argumentos lingüísticos, léxicos y estilísticos que la vinculan con la Poética, y en especial con el cap. 15, a lo que hay que añadir paralelismos como la preferencia por Homero y Sófocles como ejemplos de buenos poetas ${ }^{37}$, la importancia conferida al buen uso de los recursos poéticos, como la elocución, el pensamiento y el carácter, en la representación de los personajes ${ }^{38}$, el tratamiento de la adecuación y la verosimilitud de los caracteres en la imitación poética ${ }^{39}$, o la cita del lamento de Odiseo de Timoteo como ejemplo de inadecuación e inconveniencia en la imitación de un carácter ${ }^{40}$, muestran con claridad que el texto del papiro no sólo proviene de Aristóteles, sino además de una de sus obras de estética y teoría literaria donde se trataban y desarrollaban algunos de los temas utilizados en las lecciones del curso sobre poesía que conforma la Poética que conservamos. La única obra aristotélica de la que tenemos constancia de que se trataban temas similares a los que aparecen en la Poética es precisamente el diálogo Sobre los poetas. Si a eso añadimos que el tema del éxito y del fracaso del poeta en el uso de los

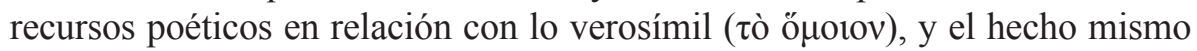
de citar a Timoteo como ejemplo de equivocación en la descripción de Odiseo, aparecen en el cap. 15 de la Poética (1454 28-31) unas líneas antes de una muy probable referencia al Sobre los poetas $\left(1454^{\mathrm{b}} 18\right)$, en la que se dice que

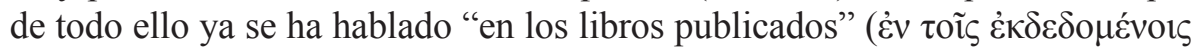
$\lambda$ ó́orc), los indicios a favor del diálogo se hacen bastante consistentes.

Otro indicio que vincula al papiro con el diálogo es la posible mención, en una columna paralela a la columna A que pertenece con toda seguridad

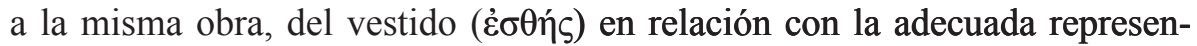
tación de los personajes ${ }^{41}$, pues sabemos que en el diálogo ${ }^{42}$ se reprochaba

${ }^{37}$ Cf. Po. $1448^{\mathrm{a}} 25-28,48^{\mathrm{b}} 28$ ss., $60^{\mathrm{b}} 34$ s.

${ }^{38}$ Cf. Po. $1449^{\mathrm{b}} 36$ ss., $59^{\mathrm{b}} 16,60^{\mathrm{b}} 1-5$.

${ }^{39}$ Cf. Po. 145422 ss.

${ }^{40}$ Cf. Po. $1454^{\text {a } 28-31 . ~}$

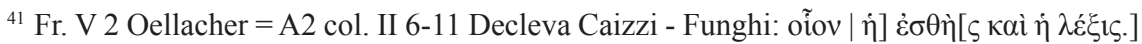

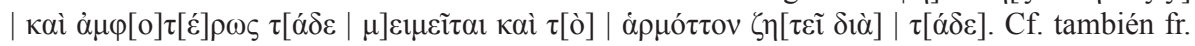

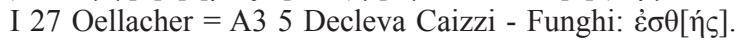

${ }^{42}$ De poetis, fr. 74 Rose $^{3}=16$ Gigon. 
a Eurípides el no saber que los etolios iban con el pie derecho descalzo, un error censurable porque afectaba a la verosimilitud de la obra ${ }^{43}$. Este paralelismo, débil por sí mismo debido al carácter conjetural del texto del papiro en el que se basa, adquiere sin embargo mucha más fuerza si tenemos en cuenta que el pasaje del diálogo en el que se censuraba la ignorancia sobre indumentaria de Eurípides se enmarcaba en un contexto más amplio, en el que se discutiría el tema del buen poeta en un doble sentido: primero, exponiéndose las condiciones de la excelencia poética; y segundo, ilustrándose con ejemplos los errores que el buen poeta debe evitar para alcanzar dicha excelencia ${ }^{44}$. En ese marco, el presente pasaje, de procedencia segura, ya que se dice expresamente que proviene del diálogo Sobre los poetas, estaría en relación tanto con la columna A del papiro, en la que se trata el mismo tema, como con dos fragmentos del libro V del Sobre los poemas de Filodemo de clara procedencia aristotélica ${ }^{45}$, en los que se define al mejor poeta de un modo similar, es decir, como aquel que es consecuente en la elaboración de argumentos, composición de caracteres y uso de la elocución.

Así pues, dado que la columna A encaja perfectamente en este contexto, y puesto que el contexto nos remite al diálogo Sobre los poetas, podemos postular como la hipótesis más probable que el texto de la columna A procede en última instancia del diálogo aristotélico. Esta conclusión no se ve contradicha en absoluto por el argumento de que el diálogo, debido a su carácter ligero y anecdótico, no podría contener un fragmento tan técnico como el del papiro, que sería más acorde con el tratamiento teórico presente en la Poética. Y ello porque, como las reconstrucciones de Rostagni, Laurenti y Janko han demostrado ${ }^{46}$, el diálogo Sobre los poetas no era una obra meramente anecdótica,

${ }^{43}$ La relación entre la mención del vestido en el papiro y el fragmento citado del diálogo ya fue puesta de manifiesto por A. Rostagni 1955b, p. 325 y, más recientemente, por R. Janko 1991, pp. 55, 64.

${ }^{44}$ Cf. A. Rostagni 1955a, pp. 298-301, R. Janko 1991, p. 53.

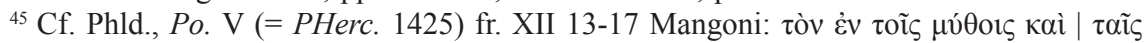

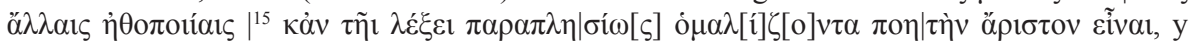

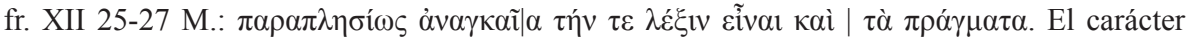
aristotélico de los fragmentos ha sido señalado por C. Jensen 1923, p. 96, R. Janko 1987, p. 191, 1991, p. 62 s. y C. Mangoni 1993, p. 215 s. Su relación con la columna A del papiro ha sido notada por Janko 1991, p. 62 s., quien argumenta convincentemente que ambos textos provienen del diálogo Sobre los poetas (cf. también Janko 1987, p. 190 y 1991, pp. 55, 64).

${ }^{46}$ A. Rostagni 1955a, pp. 255-322, R. Laurenti 1987, pp. 211-300, R. Janko 1987, pp. 175 ss., 1991, pp. 5-64 (en especial, p. 51 ss.). Cf. también O. Gigon 1987, p. 267. 
de circunstancias o de tono menor, aunque también contuviera anécdotas, noticias curiosas y digresiones biográficas, sino el primer estudio serio de Aristóteles sobre la figura del poeta y sobre el arte poética, el primer intento riguroso de construir una teoría literaria propia, en el que Aristóteles aportaba ya puntos de vista particulares y opuestos en algunos casos a Platón y a la Academia, y cuya autoridad todavía era reconocida por el propio Aristóteles cuando compuso la Poética.

En cuanto a la columna B del papiro, su probable procedencia del diálogo Sobre la filosofía descansa sobre todo en el estrecho paralelismo existente entre su tratamiento doxográfico de los primeros principios postulados por los filósofos naturales anteriores y el que se hace en el primer libro del diálogo, donde Aristóteles exponía las concepciones físicas de los pensadores precedentes, con especial atención a sus doctrinas sobre los principios de la realidad ${ }^{47}$. Asimismo, la columna B evidencia el mismo tipo de relación entre el intento de determinar el objeto y método de la filosofía natural y la alusión a los principios que constituyen el objeto principal de conocimiento de esa filosofía, que vemos en varios pasajes de la Física, de la Metafisica y del Sobre el cielo, obras que evidencian haber hecho uso del diálogo ${ }^{48}$. Además, tenemos indicios que muestran que en el diálogo también se hablaba de la filosofía natural en relación con sus principios, con la filosofía como ciencia general y con su uso por parte de los filósofos naturales precedentes para explicar la realidad ${ }^{49}$. Por otro lado, el carácter doxográfico del fragmento del papiro parece encajar mejor en un contexto como el que ofrece el primer libro del diálogo, que, por ejemplo, con los pasajes correspondientes del Protréptico que señaló Most. Y tampoco se aprecian diferencias de estilo y expresión, ya que el carácter superficial y popular de la doxografía del fragmento se daba también en el diálogo. Por tanto, considero que el diálogo Sobre la filosofia, en el estado actual de nuestros conocimientos, es la fuente más verosímil del fragmento.

En conclusión, podemos decir que las columnas A y B del papiro de Viena G 26008, constituyen un ejemplo de la dificultad que supone la determinación de la autoría y de la procedencia de fragmentos que carecen de toda indicación explícita al respecto. Sin embargo, la aplicación de criterios internos,

\footnotetext{
${ }^{47}$ Cf. p. ej. De philos. test. 4 y frr. 3, 9, 13 Untersteiner $=23$, 952, 983 Gigon.

${ }^{48}$ Cf. p. ej. De philos. frr. 9, 23, 24, 38 Untersteiner $=952,-$, 987, T 22,11 Gigon.

${ }^{49}$ Cf. el primer libro del diálogo en la edición de M. Untersteiner 1963.
} 
el análisis del lenguaje, el léxico, el estilo y el contenido, y su comparación con textos paralelos, permiten concluir con cierta certeza que se trata, o de citas literales, o de ligeras paráfrasis de textos de Aristóteles cuya fuente última son dos de sus diálogos: de la columna A, el Sobre los poetas, y de la columna B, el Sobre la filosofía. Ello es independiente del hecho de que el texto copiado en el papiro, posiblemente en un mismo rollo, pudiera proceder de una única obra de contenido doxográfico que incluyera los fragmentos de ambas columnas. La opción de proponer esos dos diálogos aristotélicos como fuente no ha sido contemplada hasta ahora por ningún editor de los diálogos de Aristóteles. No obstante, creo que los argumentos expuestos en el presente trabajo deben llevar a tomarla en consideración en el futuro en cualquier proyecto de edición de los diálogos de Aristóteles.

\section{BibliografíA}

Arrighetti, G. 1991: «Platone fra mito, poesia e storia», SCO 41, pp. 13-34.

- 1996: «önotov in un papiro di Vienna e nella 'Poetica' di Aristotele (PVindob G 26008 e Arist. Poet. 1454a24-25 e 1454b10-11)», en Serena Funghi, M. (ed.), OАOI $\triangle I Z H L I O \Sigma$. Le vie della ricerca. Studi in onore di Francesco Adorno, Florencia, pp. 59-68.

Decleva Caizzi, F.-Funghi, M. S. 1991: «Su alcuni frammenti filosofici della österreichische Nationalbibliothek (PVindob G 26008 e 29329)», en VV. AA., Varia Papyrologica, Florencia, pp. 49-99.

De Montmollin, D. 1951: La Poétique d'Aristote, Neuchâtel.

Düring, I. 1990²: Aristóteles. Exposición e interpretación de su pensamiento, trad. esp., México D. F. (= Aristoteles. Darstellung und Interpretation seines Denkens, Heidelberg, 1966).

Gigon, O. 1987: Aristotelis Opera. III. Librorum deperditorum fragmenta, Berlín.

Gomperz, T. 1886: «Eine vermeintliche Tragödie des Euripides und ein Papyrus der Sammlung Erzherzog Rainer», Anzeig. kais. Akad. der Wiss. in Wien, Wien, pp. 19-24 (= «Eine vermeintliche Tragödie des Euripides und die Kunstform des Dithyrambus», Mittheilungen aus der Sammlung der Papyrus Erzherzog Rainer, Wien, I, 1887, pp. 84-88 = Hellenika: eine Auswahl philologischer und philosophiegeschichtlicher kleiner Schriften, I, Leipzig, 1912, pp. 79-84 y Appendix, pp. 449-450).

Janko, R. 1984: Aristotle on Comedy, Londres-Berkeley-Los Ángeles.

- 1987: Aristotle. Poetics, Indianapolis-Cambridge.

- 1991: «Philodemus' On Poems and Aristotle's On Poets», CErc 21, pp. 5-64. 
Jensen, C. 1923: Philodemos über die Gedichte fünftes Buch, Berlín (= Dublín, 1973).

Laurenti, R. 1987: Aristotele. I Frammenti dei dialoghi, Nápoles.

Mangoni, C. 1993: Il quinto libro della Poetica: (PHerc. 1425 e 1538), Nápoles.

Most, G. W. 1992: «Some new fragments of Aristotle's Protrepticus?», en Studi su codici e papiri filosofici: Platone, Aristotele, Ierocle, Florencia, pp. 189-216.

Oellacher, H. 1932: «Philosophische Fragmente ästhetischen und doxographischen Inhalts», Mitteilungen aus dem Papyrussammlung der Nationalbibliothek in Wien (Papyrus Erzherzog Rainer), n. s., Viena, pp. 126-130.

- 1938: "Griechische Literarische Papyri aus der Papyrussammlung Erzherzog Rainer in Wien», Études de Papyrologie 4, pp. 135-196.

Radt, S. 1977: Tragicorum Graecorum Fragmenta (TGrF), vol. 4, «Sophocles», Gotinga.

Rose, V. 1886²: Aristotelis qui ferebantur librorum fragmenta, Leipzig (reimp., Stuttgart, 1967).

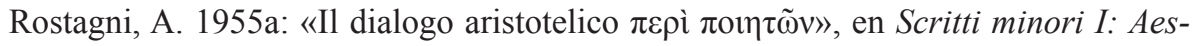
thetica, Turín, pp. 255-322 (= RFIC 54, 1926, pp. 433-470).

- 1955b: «Qualche osservazione sopra un papiro estetico-letterario attribuito ad Aristotele», en Scritti minori I: Aesthetica, Turín, pp. 323-326 (= RFIC 16, 1938, pp. 295-297).

Untersteiner, M. 1963: Aristoteles. Della Filosofia, Roma.

Fecha de recepción de la primera versión del artículo: 06/07/2007

Fecha de aceptación del artículo: 13/06/2008

Fecha de recepción de la versión definitiva del artículo: 15/06/2008

EMERITA (EM) LXXVI 1, enero-junio 2008 pp. 87-104

ISSN 0013-6662 